\title{
Improving the Installation of Offshore Wind Farms by the use of Discrete Event Simulation
}

\author{
Yohannes T. MUHABIE ${ }^{\mathrm{a}}$, Jean-David CAPRACE ${ }^{\mathrm{b}}$, Cristian PETCU ${ }^{\mathrm{a}}$, Philippe RIGO ${ }^{\mathrm{a}}$ \\ ${ }^{a}$ University of Liege, Liege, BELGIUM \\ ${ }^{\text {b }}$ Federal University of Rio de Janeiro, Rio de Janeiro, BRAZIL
}

\begin{abstract}
The offshore wind energy development is highly affected by the condition of the weather at sea. Hence, it demands a well-organized planning of the overall process starting from the producers' sites until the offshore site where the turbines will finally be installed. The planning phase can be supported with the help of Discrete Event Simulation (DES) where weather restrictions, distance matrix, vessel characteristics and assembly scenarios are taken into account. The purpose of this paper is to simulate the overall transport, assembly and installation of the wind turbine components at sea. The analysis is carried out through DES considering both the real historical weather data (wind speed and wave height) and probabilistic approach. Results of the study, applied to the real Offshore Wind Farm $(O W F)$ configuration, are showing a good agreement between the two proposed models. The results point out that the probabilistic approach is highly affected by the semi-random numbers used to model the stochastic behavior of the input variable so that several iterations (200 to 400) are required to reach the convergence of the simulation outputs. We suggest that seasonality of the outputs of both models are preserved, i.e. the variation of the results depending on the variation of the weather along the year. These findings provide a new framework to address risks and uncertainties in OWF installations.
\end{abstract}

Key words: Discrete Event Simulation (DES); Weather Time Window; Workability; Offshore Wind Farm; Lead Time, Probability, Conditional Probability, Risks

\section{INTRODUCTION}

The offshore wind energy industry is still under progress where most of the experiences are obtained from the onshore wind industry and oil \& gas industry. Offshore wind energy is one form of clean energy in which the electricity is generated from wind and connected to the grid system so that it will be used for different purposes. According to the European Wind Energy Association, $20 \%$ of the energy mix should come from renewable energy by 2020 (EWEA, 2007). It is evident that there is high potential of generating electricity from wind energy on European waters for it does not pose any visual and noise disturbance as it is far from the coast and at the same time there exists sufficient amount of wind required for electricity generation.

The average size of a grid connected offshore wind farm in 2014 was $368 \mathrm{MW}$, average water depth of wind farms completed or partially completed was 22.4 meters and the average distance to shore was $32.9 \mathrm{~km}$ (EWEA 2015).

The fact that there is tremendous amount of wind energy does not mean that it can be accessed and converted into a useful form of energy since it also has several problems like high cost of transporting and installing wind turbines, installing foundations, connecting to the grid systems, which are highly affected by weather, wind, and sea state. It was discovered (Lange,Rinne \& Haasis ,2012) that disturbances due to weather restrictions during the process of installing the turbine components at sea can lead to an explosion of logistics costs. Green and Vasilakos (2011) noted that most of the costs associated with offshore wind energy development are still much higher compared to onshore counterparts. Table 1 presents the typical cost break down of both onshore and OWFs compiled and adapted from (Henderson et al, 2003; Jungingen et al, 2004; UK government Tech. Rep, 2010; Davey et al., 2012; IRENA ,2012)

Kovacs, Erdos, Viharos and Monostori (2011) developed a model MILP, in order to treat the problem of offshore maintenance scheduling, which includes a module of an integrated framework for condition monitoring, diagnosis and maintenance.

Table 1: Typical initial-cost breakdown of a wind farm in $\%$,

\begin{tabular}{|l|c|c|}
\hline Description & Onshore & Offshore \\
\hline Wind turbines & $65-75$ & $30-50$ \\
\hline Electrical infrastructure & $1-10$ & $15-30$ \\
\hline Civil work & $0-5$ & $15-25$ \\
\hline Installation \& transport & $0-2$ & $5-30$ \\
\hline Others & 5 & 8 \\
\hline
\end{tabular}


The objective of this paper is to apply the Discrete Event Simulation (DES) for the transport and installation of offshore wind turbines. The analysis is carried out through DES considering both the real historical weather data (wind speed and wave height) and the probabilistic approach. Results of the study, applied to the real Offshore Wind Farm (OWF) configuration, are presented in the paper. The originality of this study is the fact that it considers both the historical data and the probabilistic approach in the analysis of the logistics chains in the offshore wind industry.

\section{MODEL DEVELOPMENT AND INPUT PARAMETERS}

The model maps out the activities carried out starting from the transportation of the turbine components, piles and foundation from the onshore to the offshore site where the turbines are finally erected for generating electricity. The overall operations are sub-divided into four distinct phases namely transport \& prepilling, transport \& Jacket installation, transport \& rotor assembly and transport \& turbine installation.

\section{Offshore Wind Farm}

A typical offshore wind turbine usually consists of, see Fig. 1:

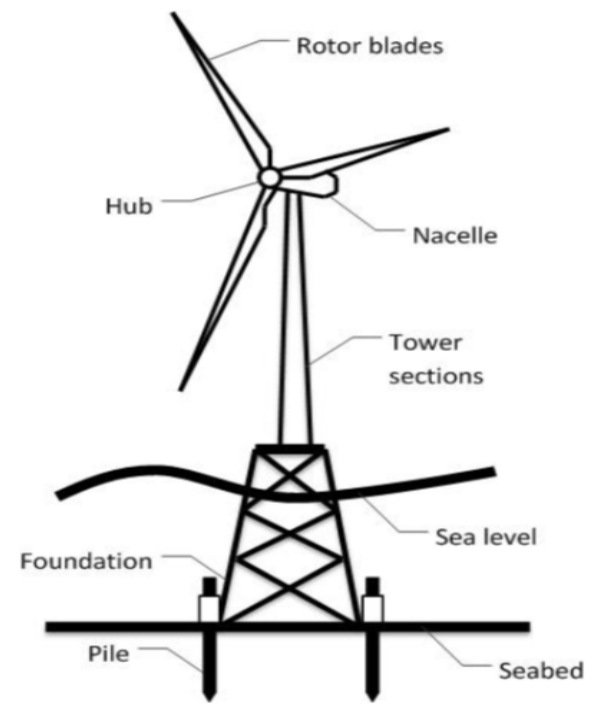

Fig. 1 Offshore wind turbine components

A. Foundation- it could be of several types, see Fig. 2. The type of foundation will determine the type of equipment required for installation. For instance, a mono pile foundation will require heavy hydraulic hammer works to drive steel pipes with diameters of 4 meters up to 20 meters in to the seabed.

a. Mono pile foundations: they can be either concrete or pre-stressed, used in shallow water, and having an advantage of low levels of noise emission during operation, low maintenance, material availability with largescale production. b. Tripod foundations: designs tend to rely on technology used by the oil and gas industry. The piles on each end are typically driven into the seabed, used for deeper depths and have not been used on many projects until now.

c. Jacket foundations: these foundations can be made of a steel framework with pile foundation, used mainly for deep water and have the advantages of lightweight and high rigidity.

d. Gravity foundations: these foundations can be made of restrained steel pile, used mainly for shallower water and have the advantage of being simple and cost efficient construction for small depths.

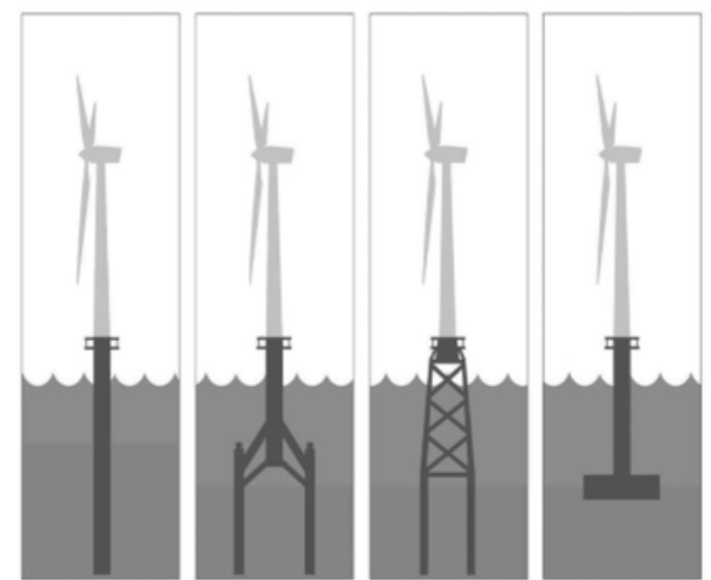

Fig 2: Types of offshore wind turbine foundations - From left to right: mono pile, tripod, jacket and gravity

B. Piles: The piles are used to fix the foundations to the seabed. During this process, a template is used when hammering or vibrating piles into the seabed. Afterwards the jacket could be lowered to the bottom of the sea where the spikes fixed at the end of the legs of the jacket fit into the piles.

C. Tower sections: have the structural role of carrying the top loads to the foundation. They are made from steel sheet rings and stiffeners (longitudinal or circular, used for rigidity purposes) protected against the strong corrosion due to seawater.

D. Nacelle: results from a combination between a steel lattice structure and fiber glass housing. The hydraulic, electrical, and electro-mechanical internal components of the nacelle (gearbox, transformers, cooling systems etc.) are integrated progressively during the construction of the nacelle. It is important to consider that the nacelle is very heavy (125 tons for a 4MW turbine). Together with the rotor, the weight of the nacelle represents a big problem in terms of lifting.

E. Rotor-hub: it corresponds to the mechanical part that joins the three blades together with the nacelle.

F. Three blades: offshore wind turbine blades are made of composite materials. At present, wind blades are 
mainly made of reinforced fiber glass. For very large blades, carbon fibers have been introduced by many manufacturers in order to reduce the weight of the structure. For a $3 \mathrm{MW}$ wind turbine, the rotor has a weight of around 100 tons and 100 meters of diameter.

There are basically two options in terms of transporting and installing the turbine components. The first option is to take all the components directly to the offshore site and install them as indicated in Fig. 3. The second option is to have an intermediate storage and assembly area where parts will be stored and if necessary pre-assembled depending on the installation strategy to be implemented so that the transportation will be carried out by another ship as indicated in Fig. 4.

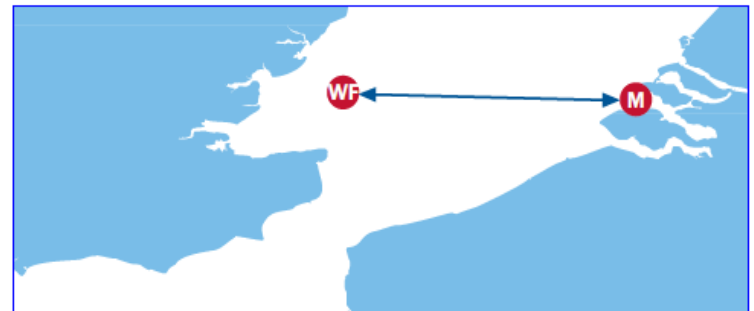

Fig. 3: First strategy to install OWF where "WF" means Wind Farm and "M" means Manufacturing

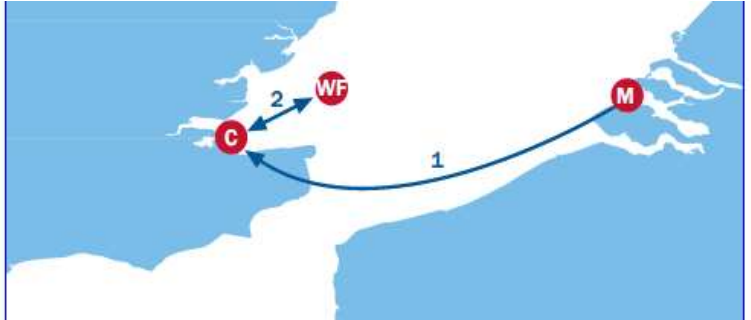

Fig. 4: Second strategy to install OWF where "WF" means Wind Farm, "C" means Center for storage and pre-assembly and "M" means Manufacturing

The number of lifts at the offshore site depends on the installation strategy selected. There are mainly three installation strategies currently used in the offshore wind industry.

1. Rotor Star: It is an installation strategy where three blades and hub will be assembled in the staging area, forming a rotor.

2. Single Blade: All the wind turbine parts will be transported to the offshore site and installed one by one.

3. Bunny Ears: This type of turbine installation requires having two blades pre-assembled forming bunny ears in the staging area and the last blade will be installed independently at the offshore site.

In this paper, the piles and jacket foundations are directly transported to the offshore site without any intermediate harbor. But the turbine parts (blades, hubs, tower sections and nacelles) are transported to the intermediate harbor where parts are stored and the assembly of the rotor is carried out (rotor star strategy).
The rotor, tower section and nacelle will finally be taken to the offshore site from this intermediate harbor.

\section{Weather Condition}

The weather at sea plays a significant role while transporting and installing wind turbine components. There are basically two factors to be fulfilled in order to carry out the operation at sea, namely:

Workability: The values (example: wind speed or wave height) above which operations will be interrupted completely.

Time Window: The range of time for which operation is possible without interruption. In general, the weather should be good enough for a certain period to accomplish a specific activity.

Table 2: Sample data sets for wind speed and wave height

\begin{tabular}{|c|c|c|c|c|c|c|c|}
\hline Year & Month & Day & Hour & Minute & $\begin{array}{c}\text { Speed } \\
\text { V1 } \\
(\mathrm{m} / \mathrm{s})\end{array}$ & $\begin{array}{c}\text { Speed } \\
\mathrm{V} 2 \\
(\mathrm{~m} / \mathrm{s})\end{array}$ & $\begin{array}{c}\text { Wave } \\
\text { height }(\mathrm{m})\end{array}$ \\
\hline 2000 & 04 & 01 & 01 & 50 & 4.06 & 4.26 & 0.36 \\
\hline 2000 & 04 & 01 & 03 & 00 & 3.48 & 3.23 & 0.40 \\
\hline 2000 & 04 & 01 & 05 & 40 & 4.2 & 4 & 0.38 \\
\hline
\end{tabular}

Table 3 Probability of good weather for a specific wind speed and wave height restrictions

\begin{tabular}{|c|c|c|c|}
\hline Month & Wind speed & Wave height & Probability (\%) \\
\hline January & \multirow{12}{*}{$<=10 \mathrm{~m} / \mathrm{s}$} & \multirow{12}{*}{$<=0.75 \mathrm{~m}$} & 13.63 \\
\hline February & & & 20.27 \\
\hline March & & & 30.09 \\
\hline April & & & 39.96 \\
\hline May & & & 34.16 \\
\hline June & & & 37.54 \\
\hline July & & & 40 \\
\hline August & & & 37.84 \\
\hline September & & & 31.74 \\
\hline October & & & 24.3 \\
\hline November & & & 14.04 \\
\hline December & & & 20.14 \\
\hline
\end{tabular}

Weather predictions and numerical weather forecasts can be calculated with different models. However, (Hinnenthal, 2007) noted that the reliable weather predictions are mostly provided for a period of approximately a maximum of 14 days. The model presented in this paper considers both the real historical data and probabilistic approach. The real offshore weather data is measured every 10 minutes and the wave height every 30 minutes for the period of April 1994 to December 2008. The dataset for the wave height has been converted into 10 minutes interval to have coherence with the wind speed datasets for analysis. The table 2 presents a sample of the wind speed and wave height datasets. 
Table 4 weather restriction for different activities

\begin{tabular}{|c|c|c|c|c|}
\hline Activity & Resource & Wind speed $(\mathrm{m} / \mathrm{s})$ & Wave height (m) & Time Window (h) \\
\hline Pile transport & Transport ship & N/A & N/A & N/A \\
\hline Pile transfer & Transport /Jack up vessel & 12 & 1.25 & 6 \\
\hline Pile driving & Jack up Vessel & 12 & 1.5 & 6 \\
\hline Jacket transport & Transport ship & 10 & 1.5 & N/A \\
\hline Jacket installation & Jack up Vessel & 12 & 0.75 & 12 \\
\hline Jacket grouting & Jack up Vessel & N/A & 1.5 & 18 \\
\hline Turbine parts transport & Transport ship & 17 & 2 & N/A \\
\hline Turbine parts transport & Jack up Vessel & 17 & 1.25 & N/A \\
\hline Lower tower installation & Jack up Vessel & 10 & N/A & 2.5 \\
\hline Upper tower and nacelle installation & Jack up Vessel & 11 & N/A & 6 \\
\hline Rotor installation & Jack up Vessel & 8 & N/A & 5 \\
\hline
\end{tabular}

Since it is not possible to have the weather forecast for more than a couple of days with high accuracy, probabilistic approach would be the best way to predict the probable data of completion for a specific project. The historical weather data of wind speed and wave height have been taken in to account in order to generate the probability of working and non-working period for a specific time window. The percentage of probability is computed by considering workability and time window parameters in a specific period (for each month). The Table 3 depicts an example of having a good weather percentage per month considering a time window of 2 hours for weather restriction of wind speed $10 \mathrm{~m} / \mathrm{s}$ and wave height $0.75 \mathrm{~m}$. Fig. 5 shows the percentage distribution of the favorable working condition of each month over the year.

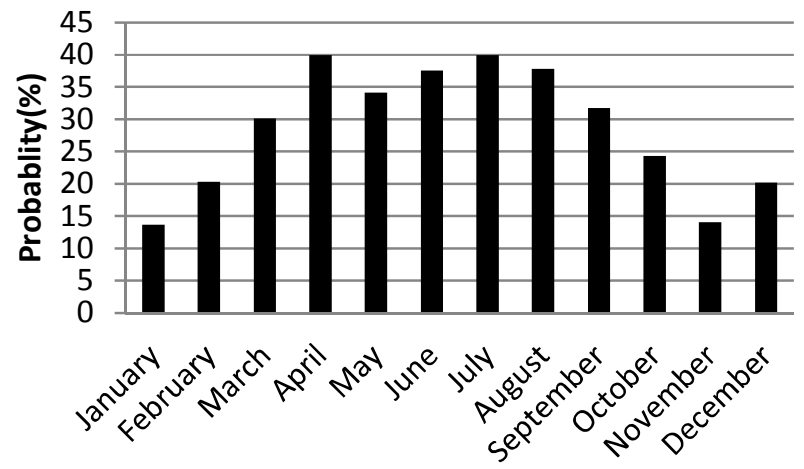

Months of the Year

Fig. 5 Probability distributions (\%) over the year for a time window of two hours with wind speed $<=10 \mathrm{~m} / \mathrm{s}$ and wave height $<=0.75 \mathrm{~m}$

\section{The Discrete Event Simulation (DES)}

DES only takes points in time (events) in to consideration. Such events may for example, be an element entering a station or leaving it, or moving on to another machine. Any movement in between is of little interest for the simulation itself. What is important is that the entrance and the exit events are assessed correctly. When the element enters a material flow object, the software calculates the time until it exits that object.

DES programs allow the mobilization of virtual plants or supply chain such as OWFs installation where product data contains all geometrical and methodical information about the wind turbines while the simulation model includes all parameters describing the production facilities, resources (machines, humans, etc.) and processes. One of the major advantages of the DES is that it is possible to integrate the operating rules of each workshop or transportation activity and simulate the complex integration between the different actors (human and material resources, transportation, machinery and tools, etc.). The DES is particularly effective to tackle problems related to the surface management, transport management, flow management (identification of bottlenecks), management of failures and hazards that a simple analytic workload simulation cannot integrate.

\section{METHODOLOGY}

The development of the tool aims to comply with the requirement of the offshore turbine transport and installation at sea. It gives an insight about the planning of the logistics activities before starting the actual construction procedures and assesses the influences of different parameters along the logistic chains (starting date, distance matrix, vessel characteristics weather restrictions etc.) on the overall project lead-time and costs of OWF's installations. A validation case has been developed in partnership with an industry that provided all the data coming from a real offshore wind farm.

The logistics flow for the "Rotor Star" installation has been presented in the Fig. 6 showing the activities used in the development of the simulation model. 


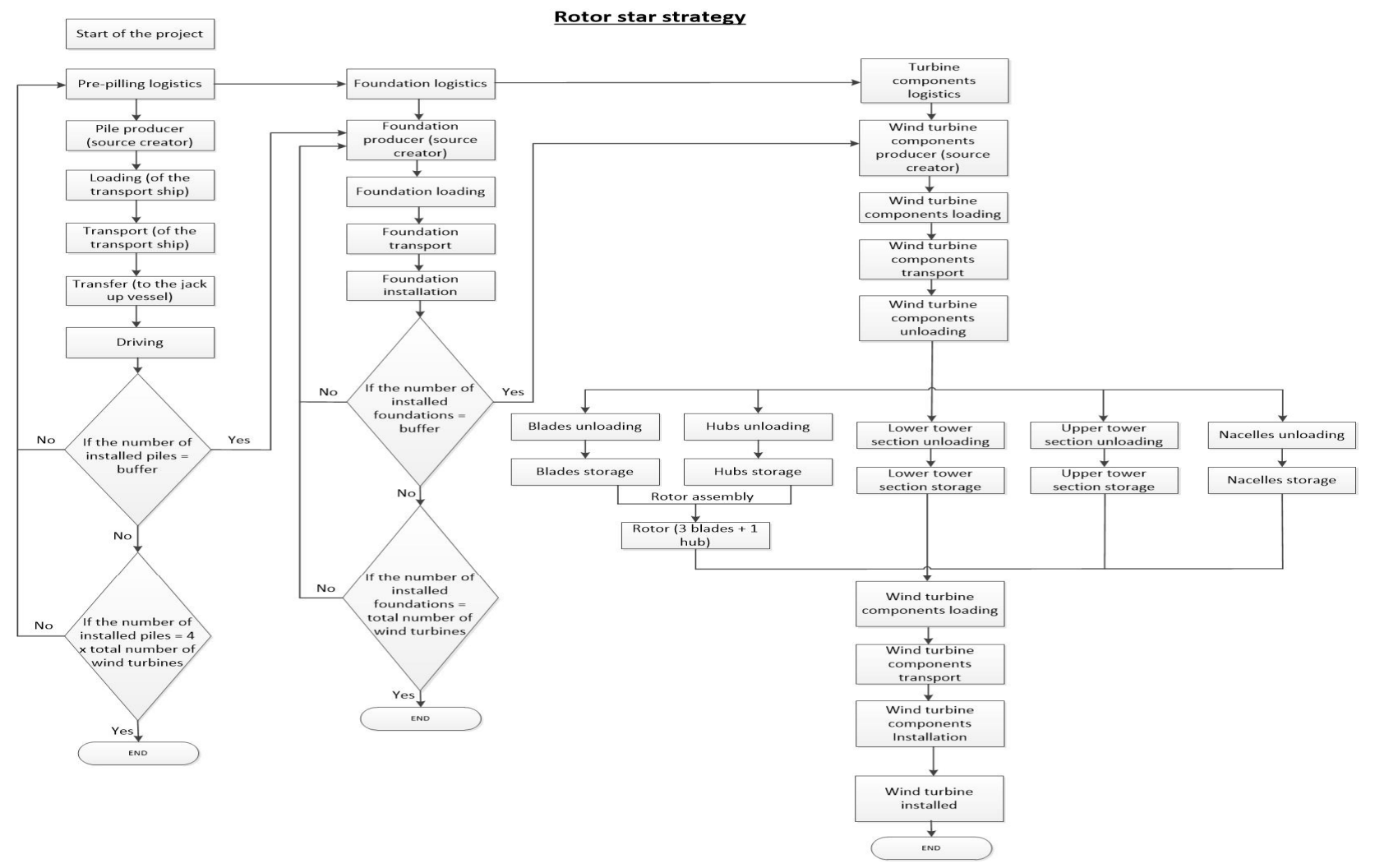

Fig .6 Model architecture for "Rotor Star" installation strategy

It is evident that the objective of any company installing OWFs is to reduce as much as possible the construction time and associated costs. The vessels, harbor facilities, cranes and labor have to be used for a specific period and any disturbance during the project execution could have a significant impact on overall cost of the project. The simulation model in this paper takes into account all the logistic disturbances along the supply chain in order to support the decision making process at the planning phase. The Fig. 7 describes the workflow of the model developed based on DES including transport, assembly, storage and installation.

Since it is not possible to exactly complete a single activity with constant process time (example: assembly of rotor star), an average process time and standard deviation of a normal distribution are considered for each process instead of constant values. Moreover, each process can also be affected by the production constraints and use of different resources (ships, crane, storage areas, etc.). The Table 5 presents the summary of the input parameters used for analyzing the results of the model.

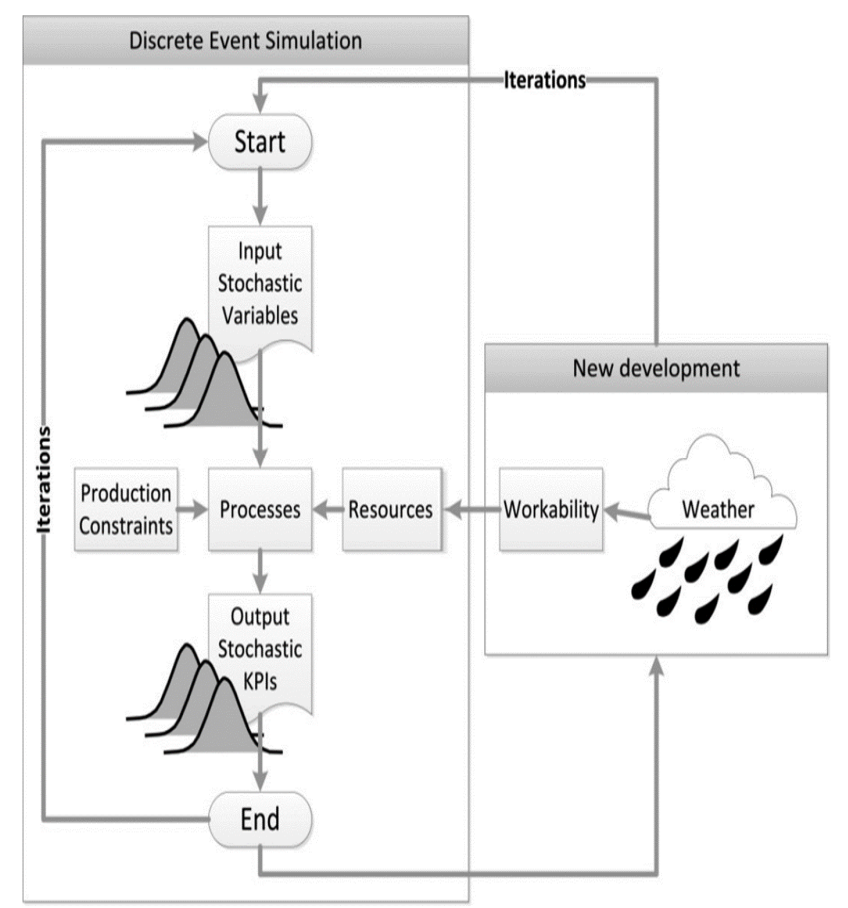

Fig. 7 Workflow of the simulation model 
Table 5 summary of input parameters

\begin{tabular}{|l|l|c|c|c|}
\hline Description & Name & Qty & Capacity(Item) & Speed (km/hr) \\
\hline Product & Wind turbine & 60 & & \\
\hline Product & Jacket foundation & 60 & & \\
\hline Product & Piles & 240 & & \\
\hline Product & Tower section & 120 & & \\
\hline Product & Rotor Hub & 60 & & \\
\hline Product & Rotor Blade & 180 & & \\
\hline Product & Nacelle & 60 & & \\
\hline Resource & Transport ship for piles & 1 & 8 & 12 \\
\hline Resource & Transport ship for foundations & 1 & 2 & 12 \\
\hline Resource & Transport ship for turbine components & 1 & 21 & 12 \\
\hline Resource & Jack up vessel for pile driving & 1 & - & 12 \\
\hline Resource & Jack up vessel for Jacket installation & 1 & - & 12 \\
\hline Resource & Jack up vessel for turbine installation & 1 & 4 & 1.5 \\
\hline Resource & Crane & 1 & 1 & \\
\hline
\end{tabular}

While considering the historical weather data, the decision for a specific activity (for example to leave the port after the ship is loaded) is taken by referring to the weather database already stored but in case of the probabilistic approach, the decision is made based on the probability of having a good weather window for a specific activity. The probabilistic approach is highly affected by the random seed number used and several iterations are required to check the convergence of the simulation results (200 to 400 iterations). The starting date of the project also affects the lead-time to complete installing a given number of wind turbines, several different start dates have been considered for both approaches and finally the results are compared.

If there are two activities to be carried out one after the other, it requires the application of conditional probability. It means the weather condition for the second activity can only be checked if there is a good weather condition for the first activity. In other words, the two activities must be completed without any interruption.

\section{RESULT AND DISCUSSION}

This section presents the results obtained by simulation for the installation of wind turbines in OWF considering both the real data and stochastic approach.

\section{Using Real Weather data}

A weather data with wind speed and wave height (every 10 minutes) for the period of 1995-2008 has been implemented in the model in order to assess the project lead-time for the installation of 60 wind turbines. The start date has been fixed to the first day of each month for each year (Example $1^{\text {st }}$ April $1995,1^{\text {st }}$ April 1996, etc.) and finally the average lead-time has been taken into account. Accordingly, Fig. 8 depicts the average lead times (in days) obtained after running several simulations together with standard deviation $(+\sigma$ and $-\sigma)$.
The average times for all the activities considered in the logistic chains have been presented in table 6 . In order to accommodate the stochastic nature of the activities in the offshore industry where the time to complete a specific activity varies, a $10 \%$ of the average time has been utilized as a standard deviation.

Table 6 Average time for different activities

\begin{tabular}{|l|c|}
\hline Activity and process & Average time (hours) \\
\hline Pile loading & 1 \\
\hline Pile transfer & 6 for 4 piles \\
\hline Pile driving & 6 per pile \\
\hline Jacket loading & 1 \\
\hline Jacket installation & 12 \\
\hline Jacket grouting & 18 \\
\hline Turbine component loading/unloading & 1 \\
\hline Lower tower installation & 2.5 \\
\hline Upper tower and nacelle installation & 6 \\
\hline Rotor installation & 5 \\
\hline
\end{tabular}

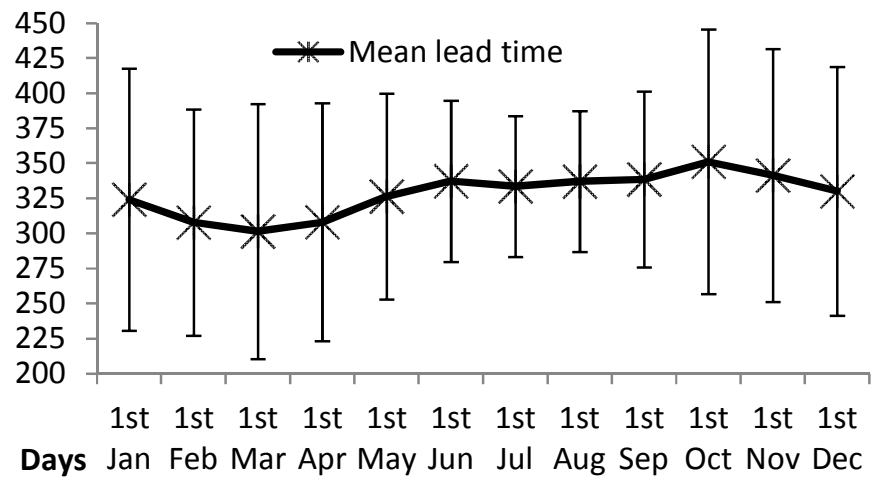

Start date of the project

Fig. 8 Mean Lead times, Mean+ Sigma, and Mean -sigma 
The Fig. 8 indicates that there is high variability in terms of lead times considering the same start date and month but different year. The minimum and maximum standard deviations are 50.2 and 94.4 days that give an insight how the weather play a significant role in the offshore wind turbine installation operations. The Fig. 9 also shows how the monthly mean value differs from the annual mean lead-time. It was found out that the maximum and minimum percentage differences are $8.12 \%$ and $0.51 \%$.

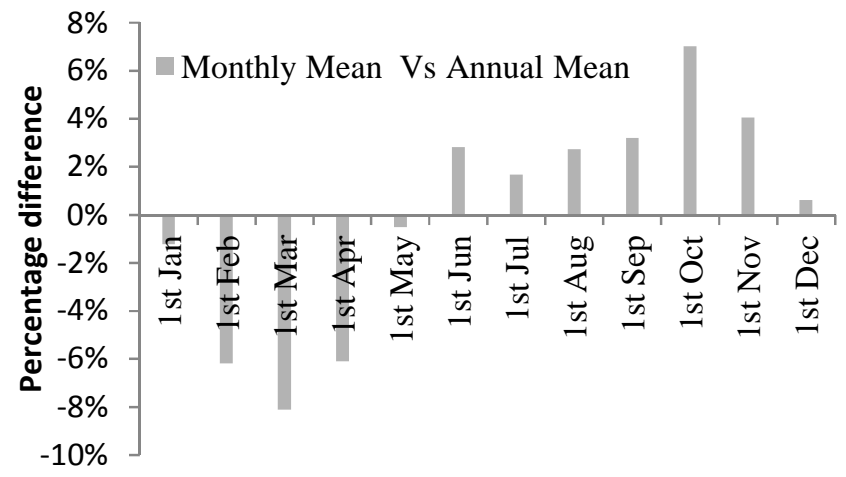

Start date of the project

Fig. 9 Percentage difference between the monthly mean lead times to the annual mean lead time (using historical data)

\section{Using Probabilistic Approach}

An example has already been depicted in the Fig. 5 about probability of working for a specific time window and this section presents the results obtained after implementing the percentage values in the model. For instance, a method will be triggered and based on the weather restriction, time window and associated probability, it gives a value of 0 or 1 (yes/no) which is considered as a deciding factor whether to proceed to the next activity or to wait until good weather exists. The loop iterates until the result is 1 (yes) which gives a green light to carry out a certain activity (sailing, installing, transferring piles, etc.). The time elapsed until the iteration gives a result of " 1 " is considered as a waiting time. Changing the random stream number will change the sequence of the binary values and it will result in having different waiting times until it reaches a green light, thereby making the output lead time stochastic (refer Fig. 10). The Fig. 11 presents a convergence test for a specific start date of the project Nov $1^{\text {st }}$. and it is clear from the Fig. 11 that the mean values tend to converge roughly after 300 iterations.

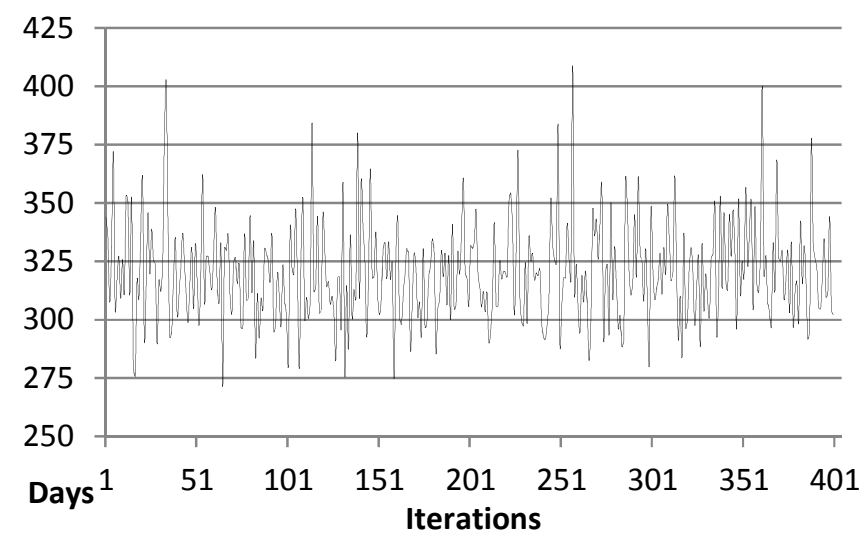

Fig. 10 Lead-time for each stochastic simulation run

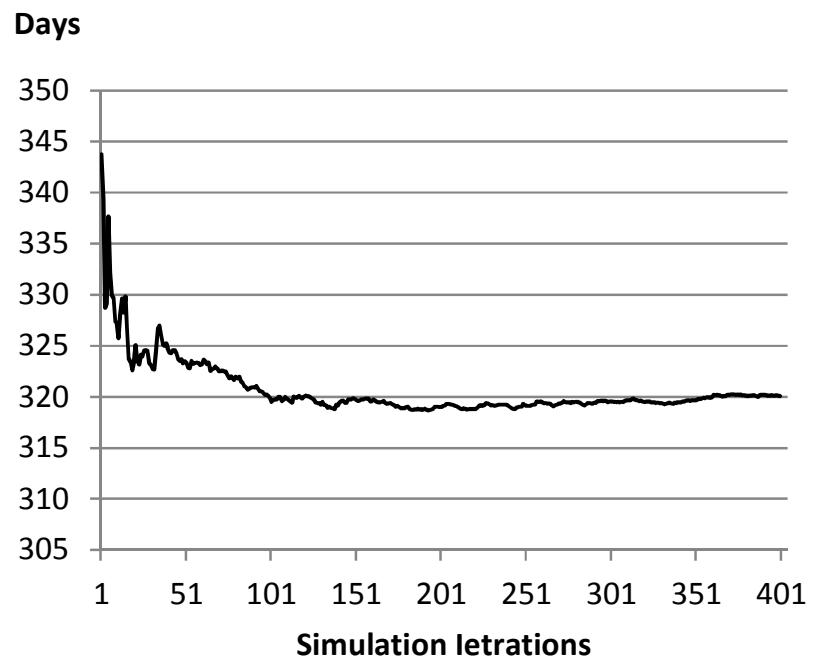

Fig. 11 Convergence test for a probabilistic approach considering $1^{\text {st }}$ of Nov as a starting date.

The Fig. 12 indicates that the minimum and maximum standard deviations are 18.2 and 35.4 days which give an insight how the weather plays a significant role in the offshore wind turbine installation operations. The Fig. 13 also shows how the monthly mean value differs from the annual mean lead-time and it was found out that the maximum and minimum percentage differences are $6.64 \%$ and $0.39 \%$. The maximum lead-time is observed when the project start data is in August and this reflects the reality since there is high weather down time during the winter season. 


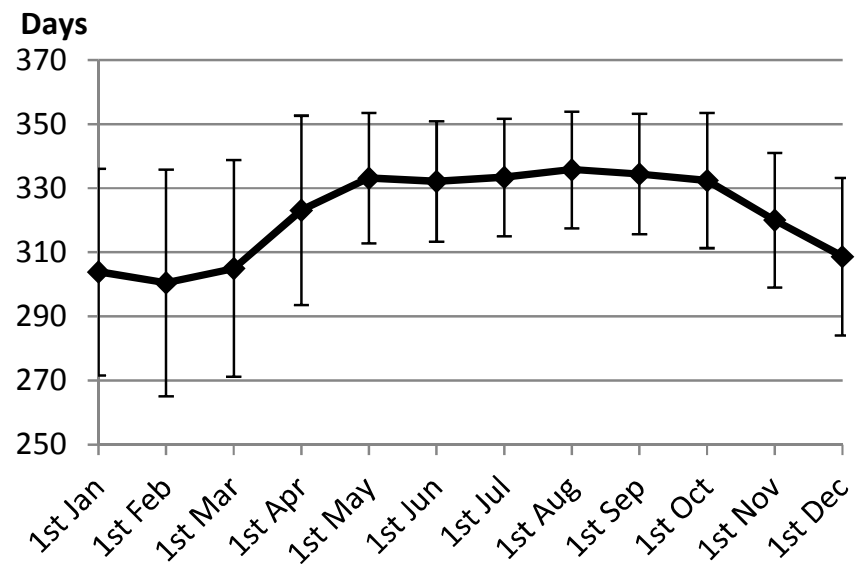

Start date of the project

Fig. 12 Mean lead times, Mean + sigma, and Mean-sigma (probabilistic approach)

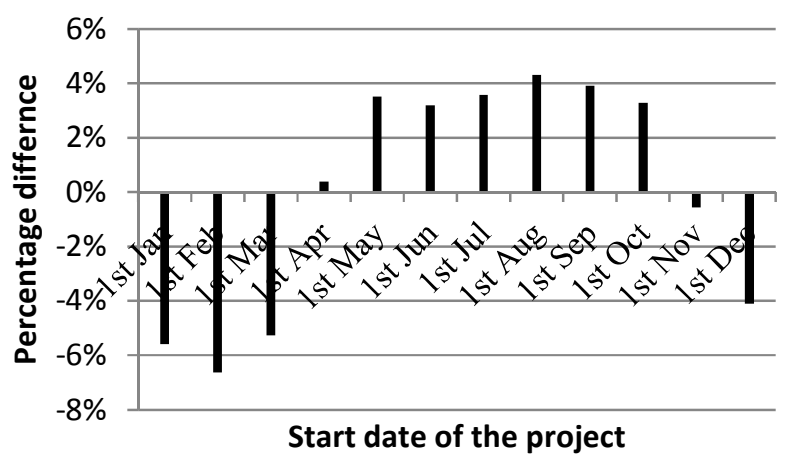

Fig. 13 Percentage difference between the monthly mean lead times to the annual mean lead-time (probabilistic approach).

The fig. 14 shows the correlation between the two approaches considered in the analysis taking the average monthly lead times over a year. The correlation coefficient found to be 0.7 .

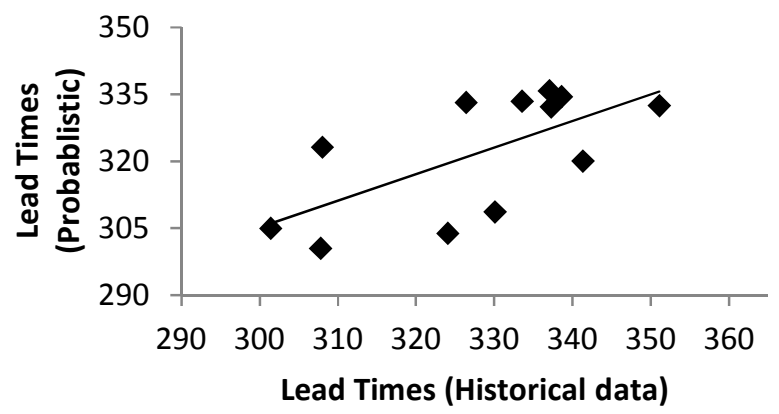

Fig. 14 Correlation between the probabilistic and historical approaches (correlation coefficient of 0.7)

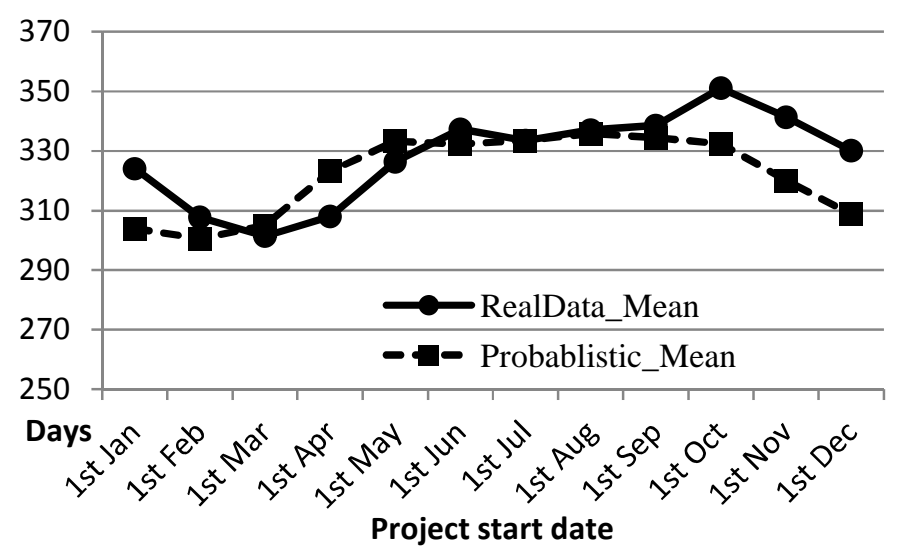

Fig. 15 Monthly average lead-time comparisons between the two approaches

The two approaches (historical data and probabilistic approach) for the transport and installation of 60 wind turbines show a good agreement considering the average mean lead-time for each month over a year (Fig. 15).

Each activity will be recorded in real time and finally shown at the end of the simulation indicating all the sub activities with their durations (loading, transporting, waiting, installation etc.). These results can be exported to the MS project platform and are very helpful in planning the overall activities for the entire project. The Fig. 16 displays a sample showing the activities and their durations. 


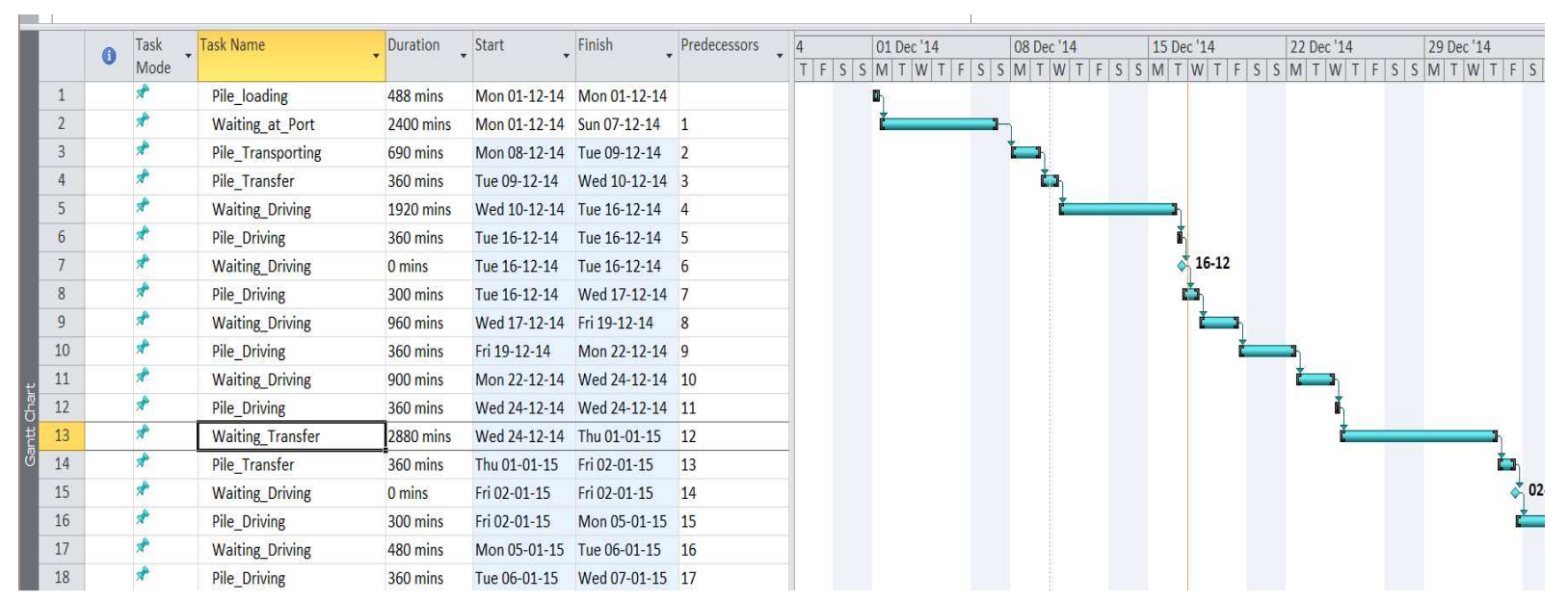

Fig. 16 Activities with their durations

In the offshore wind energy development, it is also important to see the effect of each phase (pre-pilling, jacket foundation, turbine transport and installations) on the overall logistics operations. Depending on the number of turbines to be installed and the annual weather condition at sea, the entire phase could be carried out in a single project phase or could be split into different project phases. The Fig. 17 displays the percentage of each phase for the entire project lead time considering $1^{\text {st }}$ of February as a start date (refer to Fig. 12). The phase analysis carried out revealed that the jacket phase highly affects the overall logistics chain.

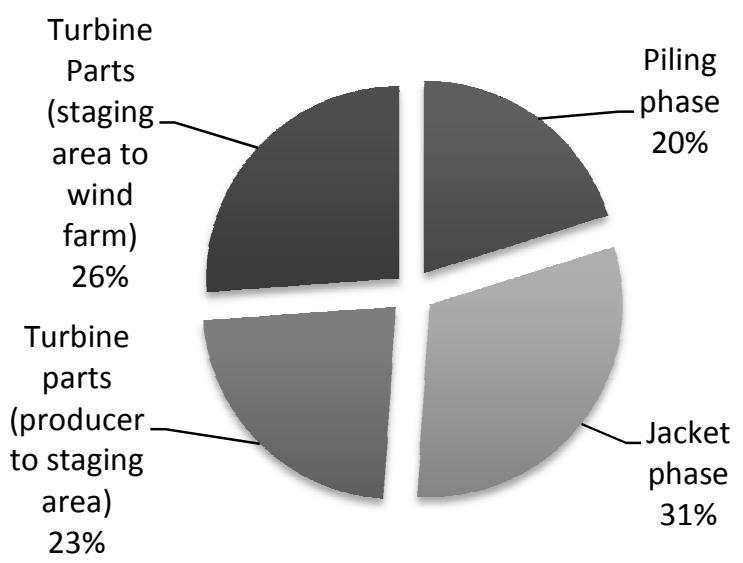

Fig. 17 Percentage of workload

\section{CONCLUSIONS and FUTURE RESEARCH}

The development of offshore wind farms is very sensitive to any disturbances along the logistics chain that could stem from not having a proper plan in advance considering the weather time window. The efficiency of the wind farm installation can be improved by making use of the DES.
The two approaches presented in this paper (historical data and probabilistic approach) for the transport and installation of turbines show a good agreement considering the average mean lead-time for each month over a year. Future wind farm projects can be supported with the help of simulation using the probabilistic approach in order to improve the planning and controlling of the logistics chains there by reducing the cost. Reducing the project lead-time also helps to get extra benefit from generating the electricity which otherwise would be used for the installation of the turbines.

It was also shown in this paper that the results can easily be exported to the MS project for further analysis and this helps to carry out the assessment of possible disturbances and project risks taking activities and sub activities into account in each phase of the project. The correlation coefficient could also be improved if more weather data (several decades) would be used as an input in the model analysis.

Future research will focus on optimization considering the type, number, capacity of vessels, installation strategies and cost of utilizing the resources within the logistics chain. It will also address the risk on schedule analysis. 


\section{REFERENCES}

A. AIT-ALLA, M.QUANDT, M.LUTJEN, Simulation-based aggregate installation planning of offshore wind farms, International Journal of Energy 7 (2013) 23-30.

A. Kovacs, G. Erdos, Z. J. Viharos, L. Monostori, A system for the detailed scheduling of wind farm maintenance, CIRP Annals - Manufacturing Technology 60 (1) (2011) 497-501.

E. Davey, a. Nimmo, Offshore wind cost reduction: Pathways study, Tech. Rep, The crow state, 16 New Burlington Place, London (May 2012).

El-Thalji, J. Liyanage, Managing offshore wind energy assets: On the systematic development of an integrated architecture, in: J. Mathew, L. Ma, A. Tan, M. Weijnen, J. Lee (Eds.), Engineering Asset Management and Infrastructure Sustainability, Springer London, 2012, pp. 181-193.

EWEA (2015), The European offshore wind industry- key trends and statistics 2014, European Wind energy Associations.

F. Thalemann, J. Bard, Offshore supply chain requirements for ocean energy in Europe-results from the orecca project, in: proceedings of the $4^{\text {th }}$ International Conference on Ocean Energy, Dublin, 2012, pp. 1-6.

Hinnenthal, Robust pareto-optimum routing of ships utilizing deterministic and ensemble weather forecasts, $\mathrm{PhD}$ thesis, Universitätsbibliothek (2007).

IRENA, Renewable Energy Technologies: Cost analysis serieswind power, Tech. Rep., International Renewable Energy agency (IRENA) (June 2012).

J. Caprace, C.Petcu, M. Velarde, P. Rigo, Towards a Risk Based Simulations for the Erection of an Offshore Windmill Park, COMPIT'12-Proceeding of the $11^{\text {th }}$ International Conference on Computer applications and Information technology in the Maritime Industries, Vol. 1, 2012, pp. 312-322.

J. Kaldellis, M. Kapasali, Shifting towards offshore wind energy-recent activity and future development, Energy Policy 53 (0) (2013) 136-148.

J. Moccia, A. Arapogianni, D. Williams, J. Philips, G. Hassan, Wind in our sails-the coming of Europe's offshore wind energy industry, Tech. Rep., The European Wind Energy Association -EWEA (2011).

J. S. Gonzlez, M. B. payn, J. M. R. santos, F. Gonzlez-Longatt, A review and recent developments in the optimal windturbine micro-sitting problems, Renewable and Sustainable Energy Reviews 30 (0) (2014) 133-144.

K. Lange, A. Rinne, H. D. Haasis, Planning maritime logistics concepts for offshore wind farms: A newly developed decision support system, in: H. Hu, X. Shi, R. Stahlbock, S. VoB (Eds.), Berlin, Springer, 2012, 142158.

L. K. Chien, S. Y. Chiu, W. C. Tseng, K. H. Chen, Risk assessment of offshore wind farm construction, in: Proceedings of the $23^{\text {rd }}$ International Offshore and Polar engineering Congress (ISOPE 13), International Society of Offshore and Polar Engineering (ISPOPE), 2013, pp. 414-420.
M. Junginger, A. Faaij, W. C. Turkenburg, Cost reduction prospects for offshore wind farms, Wind Engineering 28 (2004) 97-118.

M. Ltjen, H. Karimi, Approach of a port inventory control system for the offshore installation of wind turbines, in: The $22^{\text {th }}$ International Offshore and Polar Engineering Conference (ISOPE), Rhodes, Greece, 2012, pp. 502508.

Miller, B. Chang, R. Issa, G. Chen, Review of computer-aided numerical simulation in wind energy, Renewable and sustainable energy Reviews 25 (0) (2013) 122-134.

R. Green, N. Vasilakos, 2011, the economics of offshore wind, Energy Policy 39(2), pp. 496-502.

R. Henderson, C.Morgan, B. smith, H. C. Srensen, R.J. Barthelmi, Boesmans, Offshore Wind Energy in Europe: A review of the state-of-the-art, Wind Energy 6 (1) (2003) 35-52.

R. Perveen, N. Kishor, s. R. Mohanty, Offshore wind farm development: Present status and challenges, Renewable and Sustainable Energy reviews 29 (0) (2014) 780-792.

Scholz-Reiter, M. Lütyen, J. Heger, a. Schweizer, Planning and control of logistic for offshore wind farms, in: Proceedings of the $12^{\text {th }}$ WSEAS international conference on Mathematical and computational methods in science and engineering, MACMESE'10, World Scientific and Engineering Academy and Society (WSEAS), Stevens point, Wisconsin, USA, 2010, pp. 242-247.

Steinhauer, The simulation toolkit shipbuilding (STS)-10 years of cooperative development and inter branch application, in: V. Bertram (Ed.), proceeding of the $10^{\text {th }}$ International Conference on Computer and IT Applications in the Maritime Industries (COMPIT), Vol. 1, 2011, pp. 453-465.

T. Smit, M. Junginger, R. Smits, Technological learning in offshore wind energy: Different roles of the government, Energy Policy 35 (2007) 6431-6444

Tyapin, G. Hovland, J. Jorde, Comparison of Markov Theory and Monte Carlo Simulations for analysis of Marine Operations Related to Installation of an Offshore Wind Turbine, in : $24^{\text {th }}$ International Congress on Condition Monitoring (COMADEM), Stavanger, Norway, 2011, pp. 1071-1081.

UK, Value breakdown for the offshore wind sector, Tech. Rep. RAB (2010)0365, United Kingdom Government (February 2010)

X. Sun, D.Huang, G. Wu, The current state of Offshore wind technology development, Energy 41(1) (2012) 298 312, 23rd International Conference on Efficiency, Cost, Optimization, Simulation and Environmental Impact of Energy Systems, (ECOS). 